\title{
COMPUTATIONAL MODELLING OF COLD-FORMED STEEL SCREWED CONNECTIONS AT AMBIENT AND ELEVATED TEMPERATURES
}

\author{
Luís Mesquita ${ }^{1}$, Rui Dias ${ }^{2}$, Armandino Parente $^{2}$ and Paulo Piloto ${ }^{3}$ \\ ${ }^{1}$ ISISE, Polytechnic Institute of Braganca \\ Campus de Santa Apolónia, 5300-253 Bragança, Portugal \\ 1mesquita@ipb.pt \\ ${ }^{2}$ Polytechnic Institute of Braganca \\ Campus de Santa Apolónia, 5300-253 Bragança,, Portugal \\ \{rui_paulinho_93, armandino_parente\}@hotmail.com \\ ${ }^{3}$ LAETA-Inegi Polytechnic Institute of Braganca \\ Campus de Santa Apolónia, 5300-253 Bragança,, Portugal \\ ppiloto@ipb.pt
}

Keywords: Screwed connections, Cold-formed steel sheet, Elevated temperatures, Experimental tests, Finite element modelling.

\begin{abstract}
The application of cold-formed steel structural members in steel construction, and in particular building construction, has a number of advantages that includes its high structural efficiency compared to the member weight. In recent years the increasing safety requirements reflected in the different design standards, boosted the behaviour of materials under extreme conditions, in particular in conditions of high temperatures such as those arising from fires.
\end{abstract}

This work presents a study of the behaviour of cold-formed thin steel sheeting screwed connections at room temperature and elevated temperatures. The shear and bearing failure modes are analysed experimentally by means of a parametric analysis, considering: (i) different elevated temperature values; (ii) cold-formed steel grades; (iii) board effect of the screw position; (iv) and different steel sheet thicknesses. The set of experimental results are used for calibration and verification of the numerical model developed by the finite element method in the software Ansys.

The experimental tests presented allowed to determine the load resistance of self-drilling screwed connections of thin steel sheets and the influence of the sheet thickness, edge distance (e1) and the connection temperature. The results show that for the same connection, keeping the sheet thickness and edge distance e1, a change on the failure mode with the temperature increase occur. The finite element numerical model presented allow to study the behaviour of self-drilling screwed connections and determine the collapse load. The cases analysed give results close to the characteristic resistance of the screws manufacturer. 


\section{INTRODUCTION}

The application of cold-formed steel structural members in steel construction, and in particular building construction, has a number of advantages that includes its high structural efficiency compared to the member weight. These sections are usually obtained by thin coldformed sheets and have slender cross-sections. Although the member resistance is affected by local and distortional buckling instability phenomena, one can reduce these effects by local restraints to the partition walls panels or the building envelop panels, by means of self-drilling or self-tapping screws. Additionally the building erection phase is faster due to the ease steelto-steel connection between structural members by means of self-drilling screws.

In recent years the increasing safety requirements reflected in the different design standards, boosted the behaviour of materials under extreme conditions, in particular in conditions of high temperatures such as those arising from fires.

The design of cold-formed sections and their connection elements must be performed at room temperature and also in an accidental fire situation, for which the connection strength design value must be determined at elevated temperatures. At room temperature, bolted shear connections from bearing type category must be verified against shear and bearing failure modes. This methodology differs from that presented in EN1993-1- 3, which provides the design resistances of connections for cold-formed members and sheeting. At elevated temperatures the Annex D from EN 1993-1-2 specifies the fire design resistance of bolts loaded in shear as a function of its ambient temperature resistance (from EN1993-1-8) and a reduction factor determined for the appropriate bolt temperature.

In the case of thin steel sheets with thicknesses that typically vary between 0.5 and 3 [mm] screwed connections of these elements are carried out with self-drilling screws without the need of opening a hole, as is shown in Figure 1.
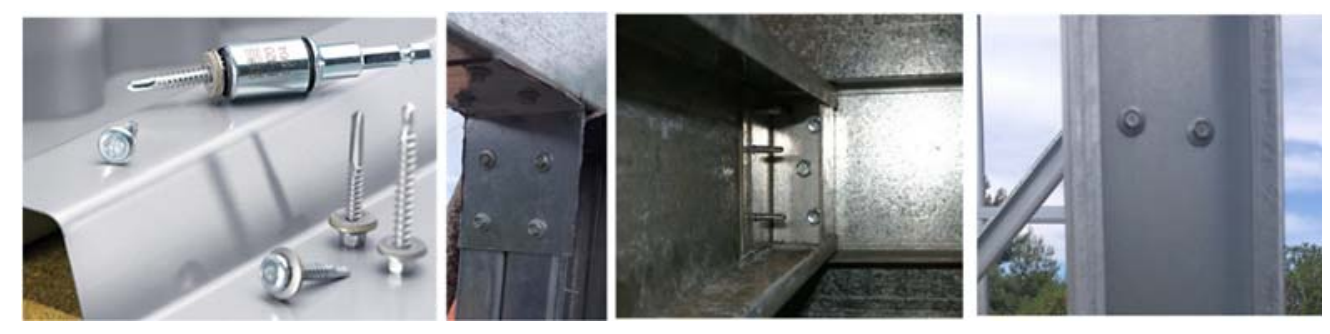

Figure 1 - Self-drilling screws in cold formed profiles.

These screwed connections behave differently than the conventional bolted connections. In the case of self-drilling screwed connections of thin steel sheets, the joint collapse load is usually determined by the bearing resistance of the plates, and only in thicker plates by the screw shear resistance. This distinction is even more noticeable in the case of structures under fire conditions. The heating rate of the thin sheets is higher than the heating rated of the screws, due to their higher thermal capacitance. Therefore, with the increase of temperature, the decrease of the bearing resistance is higher than the screw shear resistance, and may lead to a change of the collapse mode at ambient temperature.

This behaviour has already been studied by some researchers, through experimental tests and numerical simulations at ambient and elevated temperatures. Yan and Young conducted tests on bolted connections of thin sheet steels at elevated temperatures in steady state heating conditions, [1], in which the mechanical load is applied after temperature equilibrium, and also in transient state, [2], in which the connection is subject to a mechanical load and subsequent increase of temperature at constant rate. The authors analysed the effect of the bolt position and 
the influence of the bolt diameter. In addition to the test temperature and the sheets thickness, they studied the influence of one and two bolts with different positions and different bolt diameters. The results show four failure modes: namely the bolt shear, bearing, tear out and net section failure.

$\mathrm{Lu}$ et al conducted an experimental and numeric study on screwed connections at different temperature levels: $20^{\circ} \mathrm{C}, 200^{\circ} \mathrm{C}, 400^{\circ} \mathrm{C}$ e $600^{\circ} \mathrm{C}$. The results show two types of failure: (i) thin sheet bearing failure for tests under $200^{\circ} \mathrm{C}$ and (ii) screw shear failure for tests at $400^{\circ} \mathrm{C}$ and $600^{\circ} \mathrm{C}$. From this results, the authors proposed a design formula based on the EC3-1-8 rules, when the ratio between the distance of the hole to end and the diameter of the hole is between $1.00-1.75\left(1.00 \leq \mathrm{e}_{2} / \mathrm{d} \leq 1.75\right)$, [3]. The same authors also performed a numerical study of the connections using the finite element method in Abaqus software, considering an non-linear explicit analysis, [4]. The simulations consider the material and geometry nonlinearity and contact elements between the various surfaces. The bolt geometry is simplified by a simulated thread with three circumferential segments.

Chung and IP conducted a numeric study on thin sheet steel connections, form G300 and G550 sheets, using the finite element software Ansys, [5]. The numerical analyses include the elastoplastic behaviour of the material obtained experimentally and contact elements with a friction coefficient equal to 0.2 . The numerical results show that the contact stiffness and frictional coefficient between element interfaces, and clamping force in bolt shanks are important parameters for accurate prediction of bolted connections load-displacement behaviour.

This work presents a study of the behaviour of cold-formed thin steel sheeting screwed connections at room temperature and elevated temperatures. The shear and bearing failure modes are analysed experimentally by means of a parametric analysis, considering: (i) different elevated temperature values; (ii) cold-formed steel grades; (iii) board effect of the screw position; (iv) and different steel sheet thicknesses. The set of experimental results are used for calibration and verification of the numerical model developed by the finite element method in the software Ansys. The numerical method is used for a wider parametric analysis about cold-formed screwed connections at elevated temperatures. The numerical and experimental results are compared with the simplified calculation method presented in the European standards.

\section{SAFETY VERIFICATION OF BOLTED CONNECTIONS}

The design of screwed connections must be performed at room temperature and also in an accidental fire situation, in which it is necessary to know the resistance design value in function of exposure temperature. At room temperature the bolted connections loaded in shear of the bearing type, according to EN1993-1-8, should comply with the safety verifications in relation to their design shear resistance and design bearing resistance. This methodology differs from the one presented in the EN1993-1- 3 for cold-formed member connections, which provides rules for the design of self-drilling screwed connections. At elevated temperatures, the annex D of EN1993-1-2 presents the methodology to design bolted connections for shear and bearing resistance, updating the ambient temperature design resistance by a reduction factor for the appropriate bolt temperature.

\subsection{Design of bolted connections at ambient temperature.}

The design methodology of bolted connections in shear, defined as category A according to EC3 part 1.8, [6], stats that the design ultimate shear load should not exceed the design shear resistance $\left(\mathrm{F}_{\mathrm{v}, \mathrm{Ed}}<\mathrm{F}_{\mathrm{v}, \mathrm{Rd}}\right)$, nor the design bearing resistance, $\left(\mathrm{F}_{\mathrm{v}, \mathrm{Ed}}<\mathrm{F}_{\mathrm{b}, \mathrm{Rd}}\right)$. 


$$
\begin{gathered}
F_{\mathrm{v}, \mathrm{rd}}=\frac{\alpha_{v} f_{u b} A}{\gamma_{M 2}} \\
F_{b, R \mathrm{~d}}=\frac{k_{1} \alpha_{b} f_{u} d t}{\gamma_{M 2}}
\end{gathered}
$$

Where $\alpha_{v}$ represents the factor associated with the bolt class $\left(\alpha_{v}=0.6\right.$ for classes $4.6,5.6 \mathrm{e}$ $8.8, \alpha_{v}=0.5$ for classes $4.8,5.8$ e 10.9). If the shear plane passes through the threaded part of the bolt is assumed $\alpha_{v}=0.6, f_{u b}$ represents the bolt ultimate of tensile strength, A the resistant area of the bolt and $\gamma_{M 2}$ the partial safety factor for joints. The constant $\alpha_{b}$ is obtained by the smallest of $f_{u b} / f_{u}, \alpha_{d}$ or 1 . The value of $\alpha_{d}$ must be calculated for end bolts and inner bolts independently, by the following expressions, respectively:

$$
\begin{gathered}
\alpha_{\mathrm{d}}=\frac{e_{1}}{3 d_{0}} \\
\alpha_{\mathrm{d}}=\frac{p_{1}}{3 d_{0}}-\frac{1}{4}
\end{gathered}
$$

The factor $\mathrm{k}_{1}$ considers the bolt position perpendicular to the direction of load transfer. For edge bolts assume the smallest of equations (5) and (6) values and 2.5. In the case of inner bolts $\mathrm{k} 1$ is given by the smallest value between the equation (6) and 2.5.

$$
\begin{aligned}
& 2.8 \frac{e_{2}}{d_{0}}-1.7 \\
& 1.4 \frac{p_{2}}{d_{0}}-1.7
\end{aligned}
$$

Eurocode 3 part 1-3, [7], provides additional rules for safety verification of cold-formed thin steel sheets screwed connections (applied to self-drilling screws). In this case the connections bearing resistance is determined by the following equation.

$$
F_{b, R d}=\frac{\alpha f_{u} d t}{\gamma_{M 2}}
$$

The value of $\alpha$ is determined in function of the thickness of the connected plates, by the following expressions.

$$
\begin{gathered}
\alpha=3.2 \sqrt{t / d} \leq 2.1 \text { for } t=t_{1} \\
\alpha=3.2 \sqrt{t / d} \leq 2.1 \text { for } t_{1} \geq 2.5 t \text { and } t<1.0 \mathrm{~mm} \\
\alpha=2.1 \text { for } t_{1} \geq 2.5 t \text { and } t \geq 1.0 \mathrm{~mm}
\end{gathered}
$$

$t$ represents the thickness of the thinner plate and $t_{1}$ the thickness of thicker plate. In the cases not mentioned, $\alpha$ is obtained by interpolation $\left(t<t_{1}<2.5 t\right)$. The net section resistance is determined by equation 11 . 


$$
F_{n, R d}=\frac{A_{n e t} f_{u}}{\gamma_{M 2}}
$$

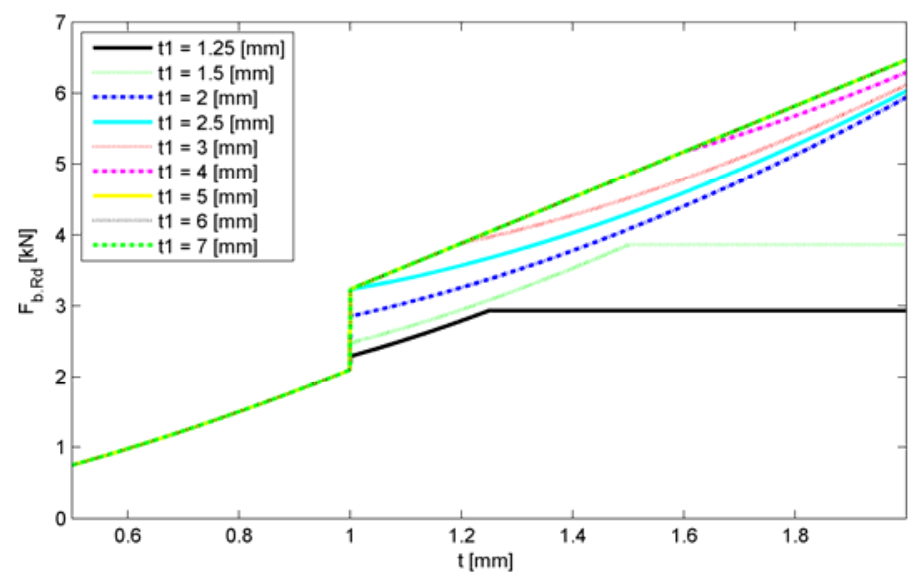

Figure 2 - Bearing resistance according to EN1993-1-3 for different steel sheet thicknesses.

Additionally, it is necessary to check the screw shear resistance. However, this part of the Eurocode defines that this resistance is determined through experimental testing, dividing the characteristic shear resistance $\left(F_{v, R k}\right)$ by the partial safety factor. This experimentally determined value, in the case of a single screw connection, is subject to the conditions presented in equation 13.

$$
\begin{gathered}
F_{v, R d}=\frac{F_{v, R k}}{\gamma_{M 2}} \\
F_{v, R d} \geq 1.2 F_{b, R d} \text { or } F_{v, R d} \geq 1.2 F_{n, R d}
\end{gathered}
$$

The experimental values are usually determined through experimental tests conducted by the screw manufacturers when the product certification is based on an European technical approval (ETA). In the case of the screws used in this study, the shear resistance characteristic values, at room temperature, are presented by SFS INTEC in ETA-10/0198 [8].

\subsection{Design of screwed connections at elevated temperatures.}

The annex D of EN 1993-1-2, [9], presents the methodology to determine the resistance of screwed connections in shear and bearing at at elevated temperatures. The net-section failure at screw holes do not need to be considered if there is a screw in each hole, because the steel temperature is lower at the connection due to the presence of additional material. The shear and bearing resistances are determined by the following equations, in which $F_{v, R d}$ and $F_{b, R d}$ are relative to the screw resistance at room temperature.

$$
\begin{aligned}
& F_{v, t, R d}=F_{v, R d} k_{b, \theta} \frac{\gamma_{M 2}}{\gamma_{M, f i}} \\
& F_{b, t, R d}=F_{b, R d} k_{b, \theta} \frac{\gamma_{M 2}}{\gamma_{M, f i}}
\end{aligned}
$$

$k_{b, \theta}$ represents the reduction coefficient for the appropriate screw temperature. This reduction value is independent of the screw strength and steel class of the connecting plates. Consequently the connection bearing resistance is determined in function of this parameter and its resistance at room temperature. Figure 3 shows the reduction coefficient temperature variation 
and its comparison with the ultimate strength $\left(k_{u, \theta}\right)$ reduction coefficient for the material G250, with $f_{y, 0.2}=292 \mathrm{MPa}$ and $f_{u}=361 \mathrm{MPa}$, determined by Kankanamge et al [10]. The next figure shows that in temperature range $400-600\left[{ }^{\circ} \mathrm{C}\right]$ the reduction coefficient $k_{b, \theta}$ increases the bearing resistance in a non-conservative way.

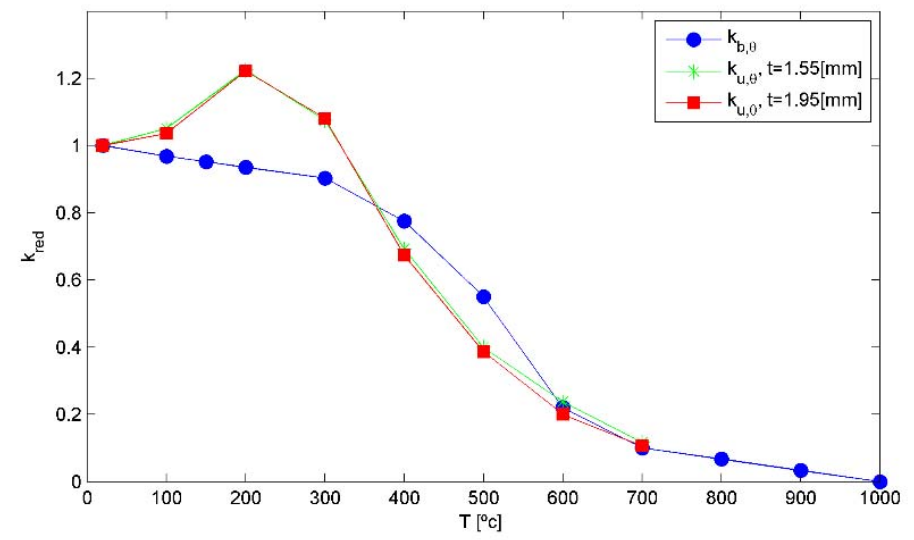

Figure 3 - Bearing resistance reduction value and comparison with the G250 ultimate strength temperature variation. [10].

\section{EXPERIMENTAL TESTS}

\subsection{Thin steel sheets screwed connections.}

This paper presents a set of experimental tests at elevated temperatures on the behaviour of screwed connections of thin steel sheets in simple shear. The galvanized steel sheets are from class DX51D $+Z(E N 10342)$ with $f_{y}=284[\mathrm{MPa}]$ and $f_{u}=355[\mathrm{MPa}]$. The connections are made with self-drilling carbon steel screws, with the reference SFS SD6-H15 Ø5,5 x $22 \mathrm{~mm}$ and a diameter of $\mathrm{D}=5,5[\mathrm{~mm}]$. The screw is placed along the middle axis of the sheet and the different distances from the end edge to the hole centre (e1): $10 \mathrm{~mm}, 15 \mathrm{~mm}$ and $20 \mathrm{~mm}$, as presented in Figure 4. A parametric study is made considering the steel sheets thickness $(1.5+1.5$, $2.0+1.5$ and $2.0+2.0[\mathrm{~mm}]$ ) and different temperature levels, representative of a fire event.

The tests presented allow the analysis of this parameters on the connection resistance and on the collapse mode.

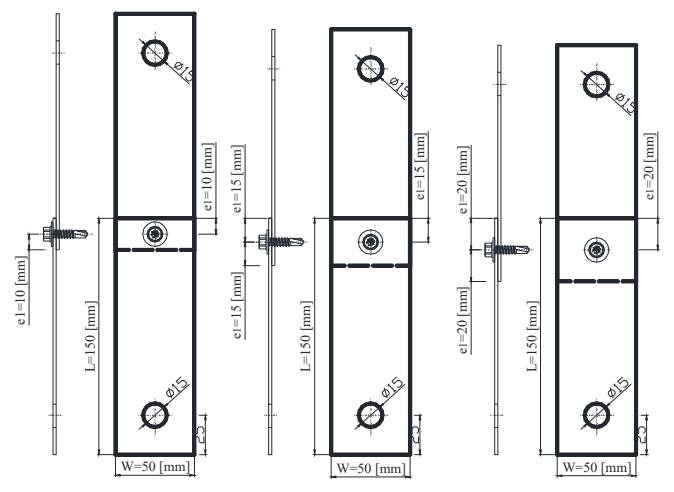

Figure 4 - Dimensions of test specimens for the screwed connections. 


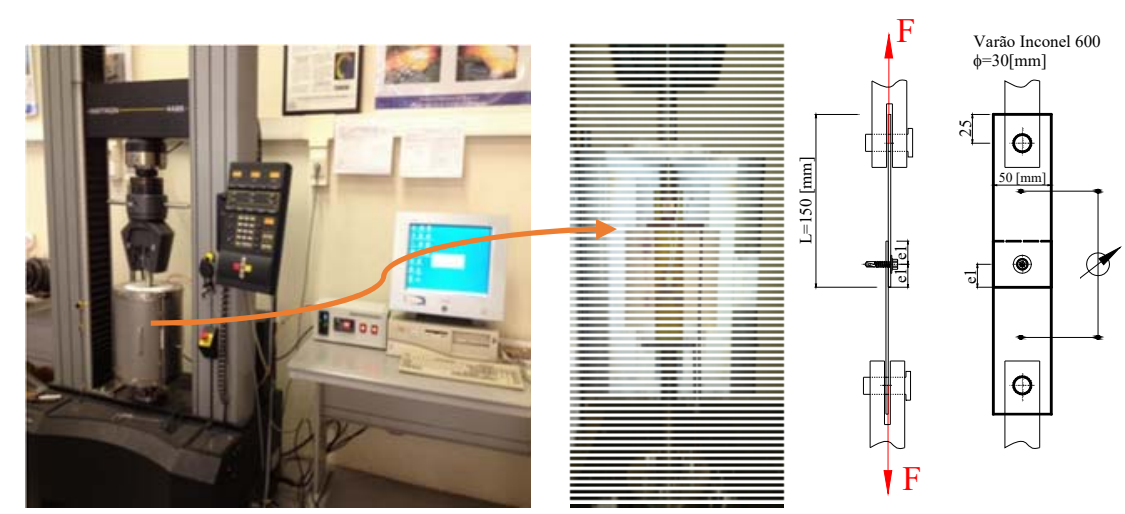

Figure 5 - Experimental setup of the screwed connections.

The experimental setup consists of a universal tensile testing machine to apply the mechanical load, (Figure 5), resulting in a shear effort to the screw. The elements are placed inside of an electric furnace, whose temperature is measured by the thermocouple type $\mathrm{K}$ and controlled by a PID system. After the set point temperature is attained, and a small initial load of approximately $0.1[\mathrm{KN}]$ is applied, the test starts with a displacement control at the velocity equal to $1[\mathrm{~mm} / \mathrm{min}]$, following the reference to the technical documentation of the ECCS, [11]. According to this procedure, the failure resistance must be defined as the peak load in a deformation of $3[\mathrm{~mm}]$, as represented in Figure 6, using an extensometer in a reference length of 150 [mm]. To measure the reference length extension two auxiliary rods, fixed to steel plates are used, allowing the mechanical extensometer be placed outside the furnace, as can be seen in Figure 5.
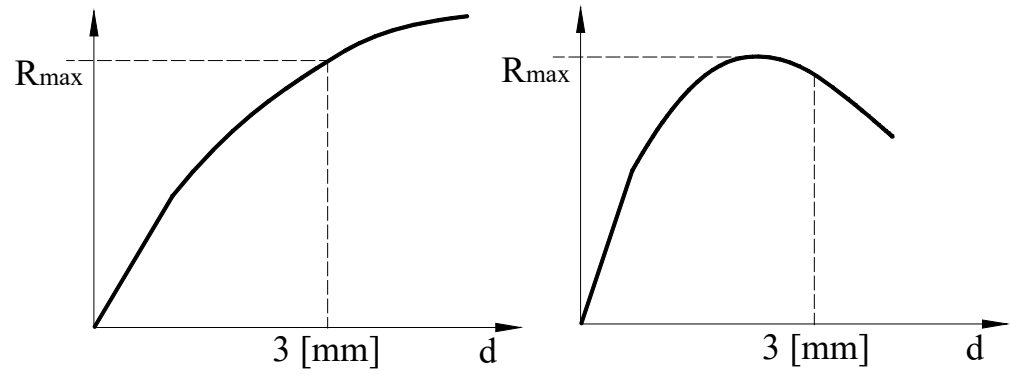

Figure 6 - Experimental tests failure limits, [11].

The failure modes obtained from self-drilling screwed connections are usually one or a combination of two failure modes presented in Figure 7. This figure presents the mechanisms of failure by shearing of the screw (SFM), bearing failure mode (BFM), which can occur with or without tearing of the steel sheet, and screw pull-out and tilting due to the screw slipping from the connection hole (TFM). In the case of thick steel sheets the expected failure mode is due to the screw shear, while for very thin steel sheets the sheet tearing or bearing is verified. Other situations may include two or more combinations of this failure modes.

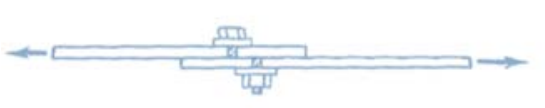

a)

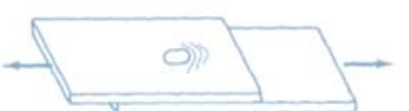

b)

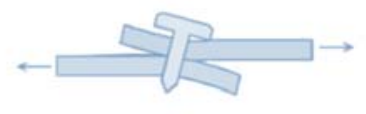

c)

Figure 7 - Failure modes: Shear failure mode (SFM), b) Bearing failure mode (BFM), c) Tilting failure mode (TFM). 
Figure 8 presents the experimental results for a combination of sheet thicknesses $1.5+1.5$ [mm], considering the applied load in function of the displacement, for different edge distances of the connection and temperature values.
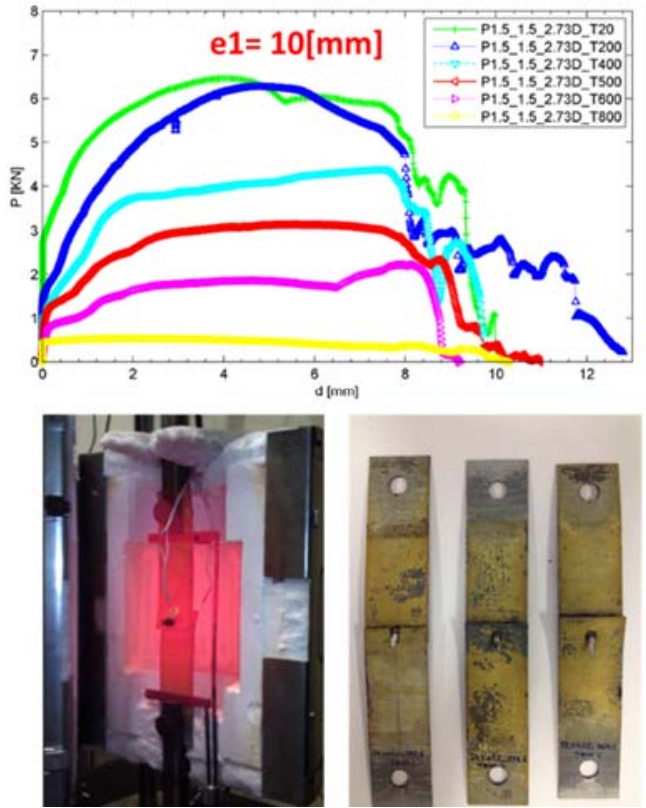
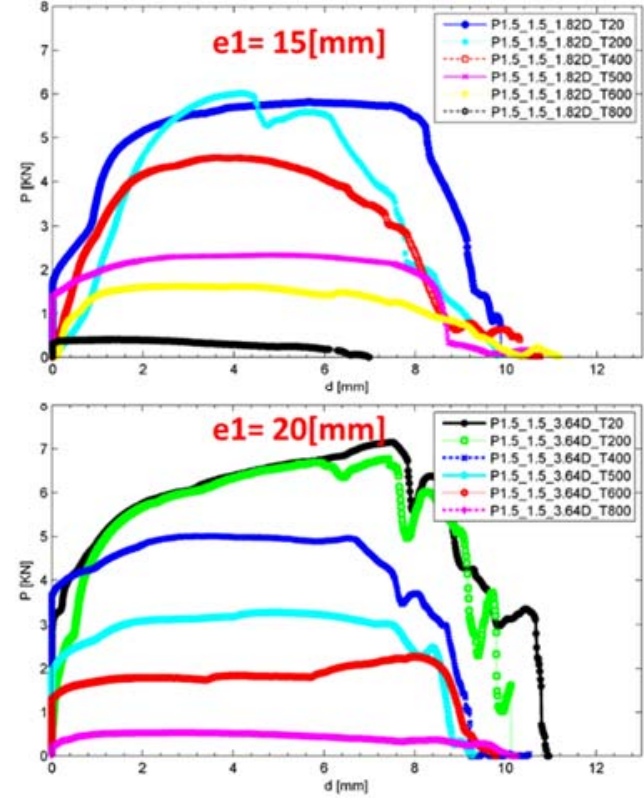

Figure 8 - Experimental results of plates $1.5+1.5[\mathrm{~mm}]$ at a temperature of 20, 200, 400, 500, 600 e $800\left[{ }^{\circ} \mathrm{C}\right]$.

In the Table 1 the experimental tests results are presented for the maximum load, the load value for $3[\mathrm{~mm}]$ displacement and the failure mode or combination of modes visualized in each test. The table also present the resistance of each connection determined from the simplified equations EC3-1-8 and EC3-1-3, presented in the previous section, considering unit partial safety factors.

The results show that, as expected, the connection resistance decreases with the temperature increase, with the exception of the $200\left[{ }^{\circ} \mathrm{C}\right]$ tests, requiring some additional tests. For the same sheet combination, $1.5+1.5$ or $2.0+1.5$, the resistance increases with the edge distance e 1 , independently of the test temperature. However, the table shows that the failure mode is mostly influenced by the edge distance $(\mathrm{e} 1)$ and the test temperature. For thinner steel sheets $(1.5+1.5)$, when an edge distance e $1=10[\mathrm{~mm}]$ is used, the failure mode is always due to bearing, while for $\mathrm{e} 1=20[\mathrm{~mm}]$ the most predominant is the tilting failure mode, where the screw rotation and sliding is attained. For the combination of steel sheets $2.0+1.5$ with an edge distance e $1=20[\mathrm{~mm}]$ the predominant failure mode is due to the screw shear, with the exception of the room temperature tests. For steel sheet thicknesses $2.0+2.0$ at a temperature of $500\left[{ }^{\circ} \mathrm{C}\right]$, the failure mode is always do to shear, regardless of the edge distance value.

\subsection{Mechanical strength of the screws steel}

The usual process of design bolted connections is based on the mechanical strength of bolts and plates material. In the case of conventional bolts, the minimum value of the bolts nominal strength (yield strength and ultimate strength) is defined by its material class, established by the standard ISO898-1:1999 [12]. In the case of self-drilling screws SFS INTEC SD6-H15 Ø5,5 x $22 \mathrm{~mm}$ a classification from this standard is unknown. According to the manufacturer, these screws are produced by cold forming a length of a steel wire from steel $18 \mathrm{~B} 2$ according to the 
EN10263. The threaded length is opened by cold working followed by a hardening heat treatment and stress relief. Finally, there is a surface treatment and dehydrogenation.

According to the manufacturer's experimental tests of the screws, the bolt tension resistant and shear resistance are 16 and 10 [KN], respectively, [13].

\begin{tabular}{|c|c|c|c|c|c|c|c|}
\hline \multirow[t]{2}{*}{ Reference } & \multirow{2}{*}{$\begin{array}{l}\mathrm{P}_{\mathrm{MAX}} \\
{[\mathrm{kN}]}\end{array}$} & \multirow{2}{*}{$\begin{array}{c}\mathrm{P}_{[\mathrm{d}=3 \mathrm{~mm}]} \\
{[\mathrm{kN}]}\end{array}$} & \multirow{2}{*}{$\begin{array}{c}\text { Failure } \\
\text { mode }\end{array}$} & \multicolumn{2}{|c|}{ EC3-1-8 } & \multicolumn{2}{|c|}{ EC3-1-3 } \\
\hline & & & & $\mathrm{Fb}, \mathrm{t}, \mathrm{Rd}$ & Fv,t,Rd & $\mathrm{Fb}, \mathrm{t}, \mathrm{Rd}$ & Fv,t,Rd \\
\hline $\mathrm{P} 1.5+1.5 \_1.82 \mathrm{~d}$-T20 & 5.820 & 5.514 & BFM & 4.438 & 6.808 & 4.894 & 3.430 \\
\hline $\mathrm{P} 1.5+1.5 \_1.82 \mathrm{~d}-\mathrm{T} 200$ & 6.008 & 5.659 & BFM & 5.432 & 8.332 & 5.991 & 4.198 \\
\hline $\mathrm{P} 1.5+1.5 \_1.82 \mathrm{~d}-\mathrm{T} 400$ & 4.537 & 4.435 & BFM & 3.075 & 4.718 & 3.392 & 2.377 \\
\hline $\mathrm{P} 1.5+1.5 \_1.82 \mathrm{~d} \_\mathrm{T} 500$ & 2.336 & 2.303 & BFM & 1.771 & 2.716 & 1.953 & 1.369 \\
\hline $\mathrm{P} 1.5+1.5 \_1.82 \mathrm{~d} \_\mathrm{T} 600$ & 1.622 & 1.616 & $\mathrm{BFM}+\mathrm{TFM}$ & 1.052 & 1.613 & 1.160 & 0.813 \\
\hline P1.5+1.5_2.73d_T20 & 6.459 & 6.266 & TFM+SFM & 6.656 & 6.808 & 4.894 & 3.430 \\
\hline P1.5+1.5_2.73d_T200 & 6.260 & 5.686 & BFM & 8.147 & 8.332 & 5.991 & 4.198 \\
\hline P1.5+1.5_2.73d_T400 & 4.387 & 3.871 & TFM & 4.613 & 4.718 & 3.392 & 2.377 \\
\hline P1.5+1.5_2.73d_T500 & 3.141 & 2.964 & TFM & 2.656 & 2.716 & 1.953 & 1.369 \\
\hline $\mathrm{P} 1.5+1.5 \_2.73 \mathrm{~d} \_\mathrm{T} 600$ & 2.223 & 1.777 & SFM & 1.578 & 1.613 & 1.160 & 0.813 \\
\hline $\mathrm{P} 1.5+1.5 \_3.64 \mathrm{~d} \_\mathrm{T} 20$ & 7.152 & 6.051 & TFM & 7.322 & 6.808 & 4.894 & 3.430 \\
\hline $\mathrm{P} 1.5+1.5 \_3.64 \mathrm{~d}-\mathrm{T} 200$ & 6.765 & 6.003 & TFM & 8.962 & 8.332 & 5.991 & 4.198 \\
\hline P1.5+1.5_3.64d_T400 & 5.004 & 4.999 & TFM & 5.074 & 4.718 & 3.392 & 2.377 \\
\hline P1.5+1.5_3.64d_T500 & 3.281 & 3.125 & TFM & 2.921 & 2.716 & 1.953 & 1.369 \\
\hline $\mathrm{P} 1.5+1.5 \_3.64 \mathrm{~d}-\mathrm{T} 600$ & 2.266 & 1.766 & SFM & 1.735 & 1.613 & 1.160 & 0.813 \\
\hline $\mathrm{P} 2.0+1.5 \_1.82 \mathrm{~d} \_\mathrm{T} 20$ & 5.750 & 5.101 & BFM & 4.438 & 6.808 & 5.173 & 4.310 \\
\hline $\mathrm{P} 2.0+1.5 \_1.82 \mathrm{~d}-\overline{\mathrm{T}} 200$ & 6.631 & 6.325 & BFM & 5.432 & 8.332 & 6.332 & 5.275 \\
\hline $\mathrm{P} 2.0+1.5 \_1.82 \mathrm{~d}_{-}^{-} \mathrm{T} 400$ & 4.977 & 4.940 & BFM & 3.075 & 4.718 & 3.585 & 2.987 \\
\hline $\mathrm{P} 2.0+1.5 \_1.82 \mathrm{~d}_{-}^{-} \mathrm{T} 500$ & 3.001 & 2.996 & BFM & 1.771 & 2.716 & 2.064 & 1.720 \\
\hline $\mathrm{P} 2.0+1.5-1.82 \mathrm{~d} \_\mathrm{T} 600$ & 1.670 & 1.664 & $\mathrm{BFM}+\mathrm{SFM}$ & 1.052 & 1.613 & 1.226 & 1.021 \\
\hline $\mathrm{P} 2.0+1.5 \_2.73 \mathrm{~d} \_\mathrm{T} 20$ & 8.086 & 6.636 & SFM & 6.656 & 6.808 & 5.173 & 4.310 \\
\hline $\mathrm{P} 2.0+1.5 \overline{2} .73 \mathrm{~d}-\overline{\mathrm{T}} 200$ & 8.666 & 7.452 & SFM & 8.147 & 8.332 & 6.332 & 5.275 \\
\hline $\mathrm{P} 2.0+1.5 \_2.73 \mathrm{~d}^{-} \mathrm{T} 400$ & 5.702 & 5.380 & $\mathrm{TFM}+\mathrm{SFM}$ & 4.613 & 4.718 & 3.585 & 2.987 \\
\hline $\mathrm{P} 2.0+1.5 \_2.73 \mathrm{~d} \_\mathrm{T} 500$ & 3.511 & 3.485 & $\mathrm{TFM}+\mathrm{SFM}$ & 2.656 & 2.716 & 2.064 & 1.720 \\
\hline $\mathrm{P} 2.0+1.5\left[2.73 \mathrm{~d}^{-} \mathrm{T} 600\right.$ & 1.863 & 1.788 & $\mathrm{TFM}+\mathrm{SFM}$ & 1.578 & 1.613 & 1.226 & 1.021 \\
\hline $\mathrm{P} 2.0+1.5 \_3.64 \mathrm{~d} \_\mathrm{T} 20$ & 8.274 & 6.481 & TFM & 7.322 & 6.808 & 5.173 & 4.310 \\
\hline $\mathrm{P} 2.0+1.5 \overline{3} .64 \mathrm{~d}-\mathrm{T} 200$ & 7.501 & 7.114 & SFM & 8.962 & 8.332 & 6.332 & 5.275 \\
\hline $\mathrm{P} 2.0+1.5\left[3.64 \mathrm{~d}_{-}^{-} \mathrm{T} 400\right.$ & 4.730 & 4.515 & $\mathrm{TFM}+\mathrm{SFM}$ & 5.074 & 4.718 & 3.585 & 2.987 \\
\hline $\mathrm{P} 2.0+1.5\left[3.64 \mathrm{~d}_{-}^{-} \mathrm{T} 500\right.$ & 3.458 & 3.426 & $\mathrm{TFM}+\mathrm{SFM}$ & 2.921 & 2.716 & 2.064 & 1.720 \\
\hline $\mathrm{P} 2.0+1.5 \quad 3.64 \mathrm{~d}$ Т 600 & 1.885 & 1.681 & TFM+SFM & 1.735 & 1.613 & 1.226 & 1.021 \\
\hline $\mathrm{P} 1.5+1.5 \_1.82 \mathrm{~d}$-T 800 & 0.397 & 0.344 & $\mathrm{BFM}$ & 0.186 & 0.285 & 0.205 & 0.144 \\
\hline $\mathrm{P} 1.5+1.5 \_2.73 \mathrm{~d} \_\mathrm{T} 800$ & 0.537 & 0.526 & TFM & 0.279 & 0.285 & 0.205 & 0.144 \\
\hline $\mathrm{P} 1.5+1.5 \quad 3.64 \mathrm{~d}^{-} \mathrm{T} 800$ & 0.532 & 0.532 & TFM & 0.307 & 0.285 & 0.205 & 0.144 \\
\hline $\mathrm{P} 2.0+2.0 \_1.82 \mathrm{~d} \_\mathrm{T} 20$ & 8.059 & 6.196 & SFM & 5.917 & 6.808 & 7.535 & 4.310 \\
\hline $\mathrm{P} 2.0+2.0 \_2.73 \mathrm{~d}$ - $\mathrm{T} 20$ & 8.977 & 5.981 & SFM & 8.875 & 6.808 & 7.535 & 4.310 \\
\hline $\mathrm{P} 2.0+2.0-3.64 \mathrm{~d}^{-} \mathrm{T} 20$ & 9.364 & 7.060 & SFM & 9.763 & 6.808 & 7.535 & 4.310 \\
\hline $\mathrm{P} 2.0+2.0 \overline{1} .82 \mathrm{~d} \overline{\mathrm{T}} 500$ & 3.474 & 3.474 & SFM & 2.361 & 2.716 & 3.007 & 1.720 \\
\hline $\mathrm{P} 2.0+2.0-2.73 \mathrm{~d}^{-} \mathrm{T} 500$ & 3.640 & 3.452 & SFM & 3.541 & 2.716 & 3.007 & 1.720 \\
\hline $\mathrm{P} 2.0+2.0-3.64 \mathrm{~d}^{-} \mathrm{T} 500$ & 3.839 & 3.650 & SFM & 3.895 & 2.716 & 3.007 & 1.720 \\
\hline
\end{tabular}

Table 1 - Characteristics and results of the experimental tests (maximum load, load at 3 [mm] of deformation and failure mode). 
With the aim of establish the classification of the screw material strength, a set of tensile experimental tests were carried out until the material rupture, using a universal testing machine. The screws were previously machined to remove the threads and to create a constant reference length with $6[\mathrm{~mm}]$ of length and $3[\mathrm{~mm}]$ of diameter. An increasing load was applied to the screw between its head and a drilled $4[\mathrm{~mm}]$ thick sheet, as shown in Figure 9. For the tests performed at elevated temperatures this setup was placed inside an electric ceramic furnace.
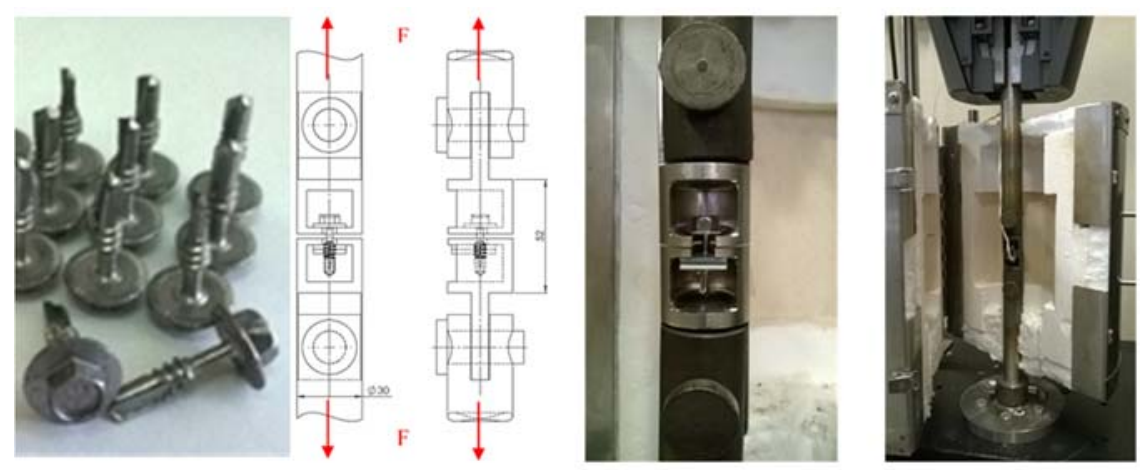

Figure 9 - Experimental setup for traction test.

Table 2 presents the average values of the experimental results of maximum load and its tensile strength for different temperature levels. The results show a noticeable reduction of the screw ultimate strength with temperature. The average results at room temperature (from a set of three) allow us to conclude that the screw meets the requirements of the minimum tensile strength for the class 10.9 .

\begin{tabular}{ccc}
\hline Temp. $\left[{ }^{\circ} \mathrm{C}\right]$ & P $_{\text {MAX }}[\mathrm{kN}]$ & Ultimate Strength $[\mathrm{Mpa}]$ \\
\hline 20 & 8,003 & 1135,67 \\
\hline 200 & 7,952 & 1125,00 \\
\hline 400 & 5,326 & 753,50 \\
\hline 500 & 3,157 & 443,9 \\
\hline
\end{tabular}

Table 2 - Average value of the screws tensile tests.

\section{NUMERICAL MODELLING OF THIN SHEET SCREWED CONNECTIONS}

The structural model used in the numerical simulations, by the finite elements method, is presented in Figure 10. This model follows the experimental setup used in the previous sections, in which one end of the steel sheet is fixed and the other is subjected to an increasing mechanical load until the collapse load is achieved. The simulations are performed in the software Ansys ${ }^{\circledR}$ considering geometric and material non-linear analysis. The structural steel elements, including the screw, are modelled using three-dimensional solid finite elements (Solid186 and Solid187) and the contact surfaces between screw-sheets and sheet-sheet modelled with contact elements (Conta174 and Targe170). All contact surfaces consider frictional contact with a friction coefficient equal to 0.2, with an Augmented Lagrange Formulation, and a refined mesh to obtain the required numeric precision of the contact between the contact and target finite elements.

The material nonlinear behaviour of the steel sheets was considered using the stress-strain curves presented in the Eurocode 3 part 1.2 at high temperatures, [9]. These curves are determined in function of the material characteristic yield stress and the temperature reduction coefficients therein presented. 


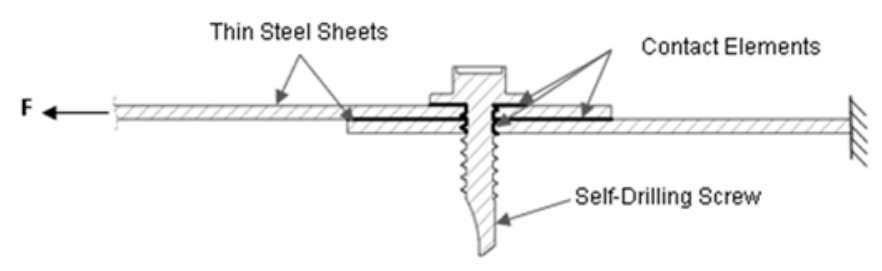

Figure 10 - Geometric model used in the numerical simulations.

In the case of thin steel sheets, being considered of class 4 , the design yield strength and its variation with temperature must be considered equal to the proportional limit strength at $0.2 \%$ deformation. For this class the temperature reduction coefficients of yield stress at $2 \%$ are not presented. This requires a modification of stress-strain curves design presented by Eurocode 3 part $1-2$, consisting in an iterative process for calculating the $2 \%$ reduction coefficients, and its yield strength in function of the temperature, so that the proportional limit strength at $0.2 \%$ match the ones from EN1993-1-2 annex E, [9].

The nonlinear material analysis performed in Ansys defined by an elastic-plastic material law, needs the stress-strain curves to be converted into true stress-true strain curves. This transformation is accomplished by the following equations, where the nominal stresses and strain values are determined by the nominal curves provided by EC3-1-2.

$$
\begin{gathered}
\varepsilon_{\text {true }}=\ln \left(1+\varepsilon_{\text {nom }}\right) \\
\sigma_{\text {true }}=\sigma_{\text {nom }}\left(1+\varepsilon_{\text {nom }}\right)
\end{gathered}
$$

The Figure 11 presents the true stress-strain curves for different temperature values of galvanized steel sheets $\mathrm{S} 350 \mathrm{GD}+\mathrm{Z}$, with a yield stress at $0.2 \%$ equal to 350 [MPa], and considering strain hardening up to $400\left[{ }^{\circ} \mathrm{C}\right]$.
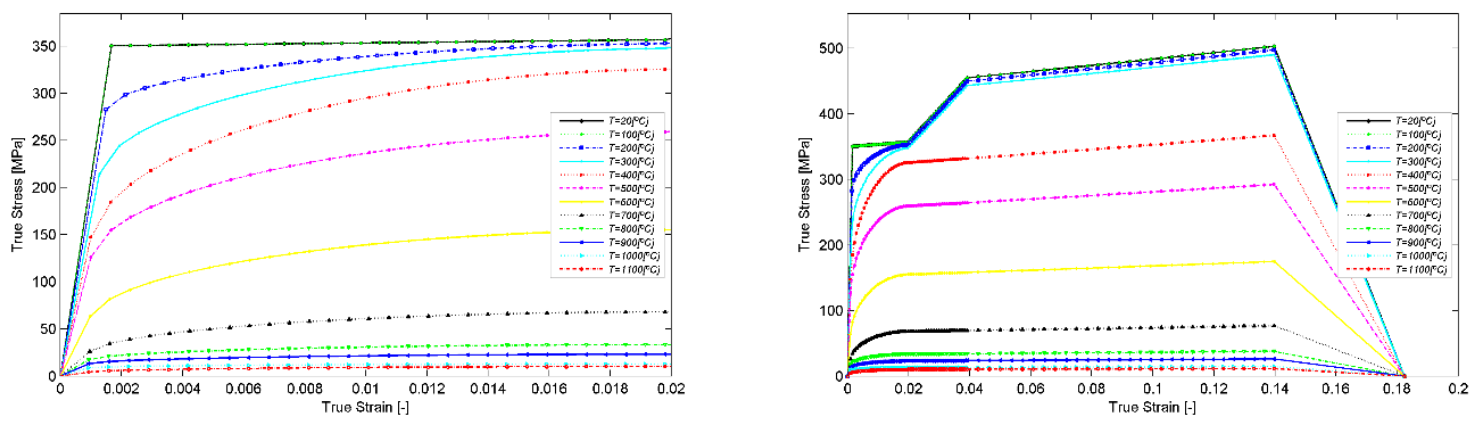

Figure 11 - True stress-strain curves for different temperatures.

As this self-drilling screws are not classified as the conventional bolts, to allow the material characterization a set of tensile tests were done to the screws in tension. The average ultimate strength value obtained was 1135.67 [MPa], allowing the screw to be classified as class 10.9, from ISO898-1:1999 [12]. The screw material stress strain curves follow a bilinear model defined by the yield strength and a tangent modulus equal to $\mathrm{E} / 100$.

\subsection{Numerical simulations.}

The simulations performed at room temperature follow a two step analysis. Firstly, without mechanical load $(\mathrm{F}=0)$, the equilibrium conditions of the contact pressure and contact conditions between the various surfaces are determined. As the experimental screw preload was not 
determined, this was not included in the numerical analysis. The second step consists in applying a linearly increasing load, with minimum increments of $1[\mathrm{~N}]$, while the equilibrium condition are attained, obtaining the connection collapse load at the end of the simulation.

Figure 12 presents the finite element model of two thin steel sheets $(1+2[\mathrm{~mm}])$ screwed connection considering an edge distance equal to $20[\mathrm{~mm}]$. To reduce the finite element model and its computational time a symmetry condition was used. The Von Mises equivalent stress distribution show the yielding of the sheets due to bearing, with stress values higher than the yield stress, and a small plastic area along the screw thread, with stresses over 900 [MPa]. The connection collapse load applied at this instant is 4693.4 [N]. The numerical results from simulations performed with a steel sheets combination equal to $2+2[\mathrm{~mm}]$ allow to obtain a collapse load of $5600[\mathrm{~N}]$.

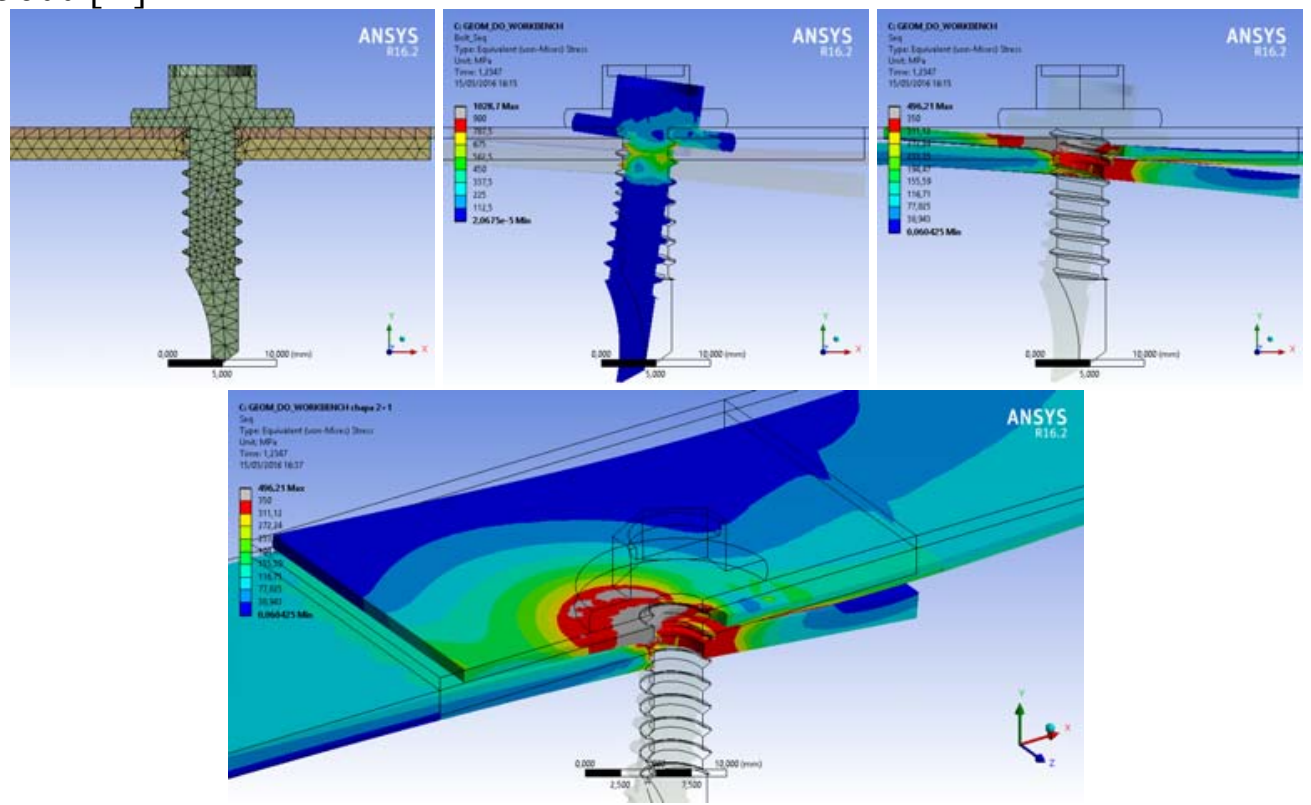

Figure 12 - Finite element model of steel sheets $2+1[\mathrm{~mm}]$. Steel sheets and screw von Mises equivalent stress distribution at the collapse load.

\section{CONCLUSIONS}

- The experimental tests presented allowed to determine the load resistance of self-drilling screwed connections of thin steel sheets and the influence of the sheet thickness, edge distance (e1) and the connection temperature.

- For the same connection, keeping the sheet thickness and edge distance e1, we can observe a change on the failure mode with the temperature increase. The three failure modes were detected, being mainly the screw shear failure, steel sheets bearing failure and a combination of both.

- Connections with double steel sheets of $2.0[\mathrm{~mm}]$ have a failure mode due to screw shear at ambient temperature and at $500\left[{ }^{\circ} \mathrm{C}\right]$. Connections with double steel sheets of $1.5[\mathrm{~mm}]$, the failure mode varies with the edge distance el and changes from steel sheets bearing failure to a combination of tilting and screw shearing at higher temperatures.

- The finite element numerical model shown allow to study the behaviour of self-drilling screwed connections and determine the collapse load. The cases analysed give results close to the characteristic resistance of the screws manufacturer.

- Further experimental tests are being planned for a parametric analysis of the steel sheet material class (SGD220, SGD280, SGD320 and SGD350) with different sheet thicknesses. 


\section{ACKNOWLEDGEMENTS}

The authors acknowledge the support and the supply of materials used in the study from the companies SFS INTEC, LUSOSIDER and IRMALEX.

\section{REFERENCES}

[1] Yan, S. and B. Young, Tests of single shear bolted connections of thin sheet steels at elevated temperatures - Part I: Steady state tests. Thin-Walled Structures, 2011. 49(10): p. 1320-1333.

[2] Yan, S. and B. Young, Tests of single shear bolted connections of thin sheet steels at elevated temperatures-Part II: Transient state tests. Thin-Walled Structures, 2011. 49(10): p. 1334-1340.

[3] Lu, W., et al., Design of screwed steel sheeting connection at ambient and elevated temperatures. Thin-Walled Structures, 2011. 49(12): p. 1526-1533.

[4] Lu, W., et al., Behaviour of shear connectors in cold-formed steel sheeting at ambient and elevated temperatures. Thin-Walled Structures, 2012. 61: p. 229-238.

[5] Chung, K.F. and K.H. Ip, Finite element modeling of bolted connections between coldformed steel strips and hot rolled steel plates under static shear loading. Engineering Structures, 2000. 22(10): p. 1271-1284.

[6] Portugal. Instituto Português da Qualidade, Eurocódigo 3 projecto de estruturas de aço Parte 1-8 projecto de ligações NP EN 1993-1-8: 2010. 2010, Caparica: IPQ. 146 p.

[7] CEN, EN1993-1-3 Eurocode 3 : Design of steel structures, Part 1-3: General rules Supplementary rules for cold-formed members and sheeting. 2004, European Committee for Standardization: Brussels, Belgium.

[8] EOTA, ETA-10/0198 Fastening screws for metal members and sheeting, Fastening screws SFS, SFS intec AG. 2013: European Organisation for Technical Approvals.

[9] IPQ, Eurocódigo 3 projecto de estruturas de aço Parte 1-2 regras gerais. Verificação da resistência ao fogo NP EN 1993-1-2: 2010, ed. Instituto Português da Qualidade. 2010, Caparica: IPQ. 87 p.

[10] Kankanamge, N.D. and M. Mahendran, Mechanical properties of cold-formed steels at elevated temperatures. Thin-Walled Structures, 2011. 49(1): p. 26-44.

[11] ECCS-TC7, ECCS TC 7: The Testing of Connections with Mechanical Fasteners in Steel Sheeting and Sections. Vol. N ${ }^{\circ}$ 124. 2009, Brussels: Brussels.

[12] Standardization, E.C.f., EN ISO 898-1:1999 - Mechanical properties of fasteners made of carbon steel and alloy steel - Part 1: Bolts, screws and studs. 1999.

[13] SFS-INTEC, Technical performance values for SFS fasteners, SFS-INTEC, Editor. 2000: Prestbury. 